\title{
The Linkage between Imported Energy and Trade in Taiwan
}

\author{
Jin-Li Hu, ${ }^{1}$ Tzu-Pu Chang, ${ }^{2}$ Fang-Yu Yeh, ${ }^{3}$ and Tzu-Cheng Yang ${ }^{1}$ \\ ${ }^{1}$ Institute of Business and Management, National Chiao Tung University, 118 Chung-Hsiao W. Road, Section 1, \\ Taipei City 100, Taiwan \\ ${ }^{2}$ Institute of Economics, Academia Sinica, Taipei City 11529, Taiwan \\ ${ }^{3}$ Science \& Technology Policy Research and Information Center, National Applied Research Laboratories, Taipei City 10636, Taiwan
}

Correspondence should be addressed to Jin-Li Hu, jinlihu@yahoo.com

Received 14 April 2012; Accepted 21 June 2012

Academic Editors: S. Cameron and B. M. Tabak

Copyright (C) 2012 Jin-Li Hu et al. This is an open access article distributed under the Creative Commons Attribution License, which permits unrestricted use, distribution, and reproduction in any medium, provided the original work is properly cited.

\begin{abstract}
This study examines the Granger causality between Taiwan's aggregate and disaggregate energy consumption and trade variables, including total imports (IM), total exports (EX), total energy consumption (ENERGY), oil and petroleum products consumption (OIL), coal and coal products consumption (COAL), natural gas consumption (GAS), export value of the industrial sector (EX_I), export value of heavy-chemical industrial products (EX_HI), and export value of non-heavy-chemical industrial products (EX_NHI) with monthly data during 1998-2009. Via applying Hsiao's version of the Granger causality method, the results find causality running from ENERGY to IM, EX, EX_I, and EX_HI. The impulse-response simulations show that the above relations have positive responses at the initial period. OIL Granger causes all trade variables. The impulse directions to IM and EX_NHI are negative, whereas others are positive. On the other hand, COAL responds to impulses in all trade variables. The impulse-response simulations show that these relations have positive responses at the initial period except for causality running from EX_HI and EX_NHI to COAL. GAS positively responds to impulses in EX, EX_I, and EX_HI at the initial period. The bidirectional Granger causality between pairs of variables (such as GAS and EX_NHI as well as GAS and EX_HI) is found.
\end{abstract}

\section{Introduction}

The 1973 energy crisis prompted countries all over the world to see the importance of energy to national security as well as economic development. Moreover, greenhouse gases produced by energy consumption have had drastic impacts on global climate change, attracting attention and efforts under the UN Framework Convention on Climate Change.

Since domestic energy sources in Taiwan are scarce, Taiwan's dependence on imported energy was rated up at $99.34 \%$ in 2008 [1]. The cost of imported energy accounts for $11.31 \%$ of Taiwan's GDP [2]. Total energy consumption has grown greatly over the past two decades, going from 48.04 million kiloliters of oil equivalent (KLOE) in 1989 to 113.09 million kiloliters in 2009, which is an average annual growth of $4.41 \%$ (Table 1) [3]. In the face of a constant rise in energy prices, the heavy cost of imported energy impacts not only household expenditures, but also the country's overall economic growth $[4,5]$. As international energy prices skyrocket, they raise the production costs for energyconsuming industries and hence directly reduce firms' profit margins and production.

Taiwan's primary imported energy resources are petroleum, coal, and natural gas, accounting for $49.45 \%$, $32.42 \%$, and $9.42 \%$, respectively, of the value of energy imports in 2009. For energy demand, the biggest share in energy consumption belongs to electricity (49.28\%) followed by oil products $(41.35 \%)$, coal products $(6.81 \%)$, natural gas $(2.20 \%)$, solar energy $(0.10 \%)$, and others $(0.26 \%)$ (Figure 1$)$. Since electricity price is fixed and the components of it are not clear, this study does not use it as an observation variable. In addition, energy consumption in the industrial sector accounts for $52.48 \%$ of total energy consumption (Figure 2) and up to $98 \%$ in the value of total exports.

Although the relation between energy consumption and economic growth has been analyzed by prior literature, this paper investigates the linkage between energy consumption 
TABLE 1: Total domestic energy consumption quantity and growth rate.

\begin{tabular}{lcc}
\hline Year & Quantity $\left(10^{3}\right.$ KLOE $)$ & Growth rate $(\%)$ \\
\hline 1989 & $48,035.8$ & - \\
1990 & $50,986.7$ & 6.14 \\
1991 & $54,554.7$ & 7.00 \\
1992 & $57,952.6$ & 6.23 \\
1993 & $60,745.1$ & 4.82 \\
1994 & $65,021.4$ & 7.04 \\
1995 & $68,475.5$ & 5.31 \\
1996 & $71,754.8$ & 4.79 \\
1997 & $75,357.3$ & 5.02 \\
1998 & $80,291.0$ & 6.55 \\
1999 & $84,645.1$ & 5.42 \\
2000 & $91,736.5$ & 8.38 \\
2001 & $97,055.2$ & 5.80 \\
2002 & $100,495.0$ & 3.54 \\
2003 & $104,371.5$ & 3.86 \\
2004 & $108,766.3$ & 4.21 \\
2005 & $111,143.5$ & 2.19 \\
2006 & $113,738.6$ & 2.33 \\
2007 & $119,175.8$ & 4.78 \\
2008 & $115,701.2$ & -2.92 \\
2009 & $113,085.2$ & -2.26 \\
\hline Average & $85,385.2$ & 4.41 \\
\hline
\end{tabular}

Data source: [3].

Note: KLOE is kiloliters of oil equivalent.

and international trade in Taiwan, because Taiwan is an economy as its degree of dependence on foreign trade is almost $100 \%(99.91 \%)$ in 2009. Some articles discuss the relations between international trade variables and economic growth, such as Ghartey [6], Kwan et al. [7], and Shirazi and Manap [8]. Furthermore, international trade is an important factor shaping the industrial structure of a country and consequently affects a country's energy use and $\mathrm{CO}_{2}$ emissions [9]. In other words, imported energy prices may not only slow down the development of Taiwan's industrial sector, but also influence its trade surplus. (Trade surplus is an index measuring the difference in value between total exports and total imports of an economy during a specific period of time, and it will be used as one of this work's research variables.)

The reminder of this study is organized as follows. Section 2 reviews the related literature and addresses the framework of this paper. Section 3 briefly describes the econometric method applied in this study. Section 4 presents data, descriptive statistics, and empirical results. Concluding remarks are given in the final section.

\section{Literature Review and Research Framework}

Kraft and Kraft [10] address the idea of a causal relationship between energy consumption and economic growth for the USA, and it is one of the earliest paper examining the relationship between these variables. Considerable attention

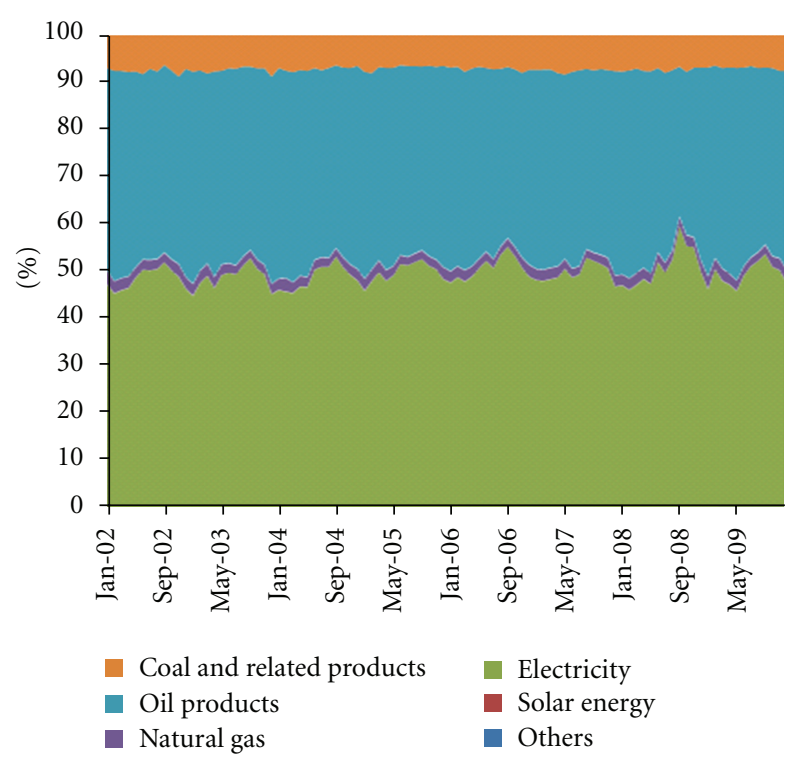

FIGURE 1: Energy consumption structure in Taiwan (by energy types). Data source: [1].

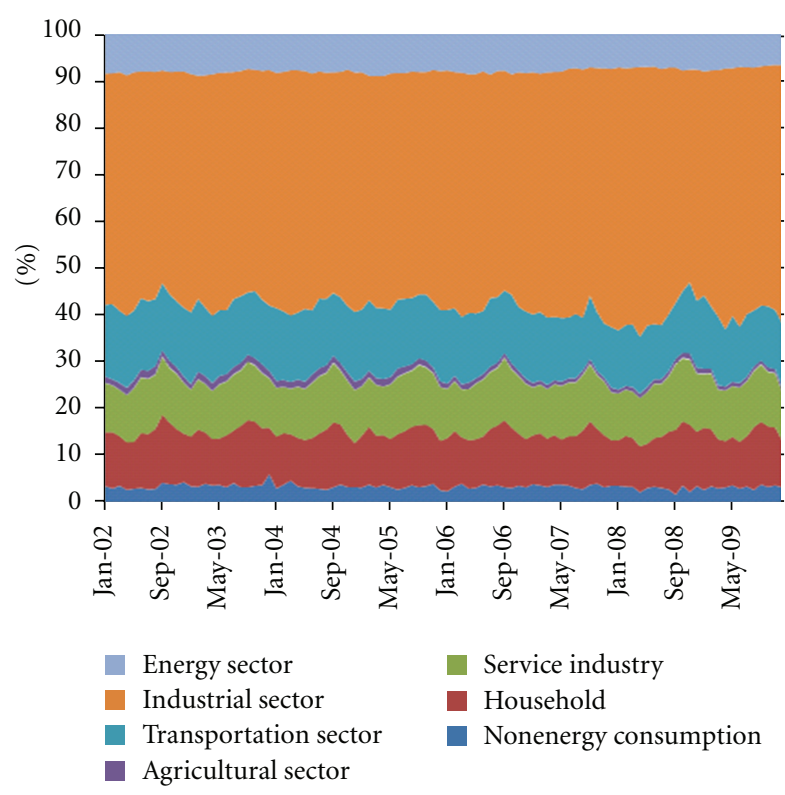

FIgURE 2: Energy consumption structure in Taiwan (by sectors). Data source: [1].

recently still has focused on this kind of relationship. In general, these related studies can be divided into four types, and this study presents these four categories to make a brief literature review.

The first category finds causality running from energy consumption to economic growth, and it is referred to as "the growth hypothesis". Ang [11] observes that the causal relation running from energy use to GDP appears in the short run in France with the cointegration approach and VEC model. Through a modified version of the Granger causality approach called the Toda-Yamamoto causality test, 


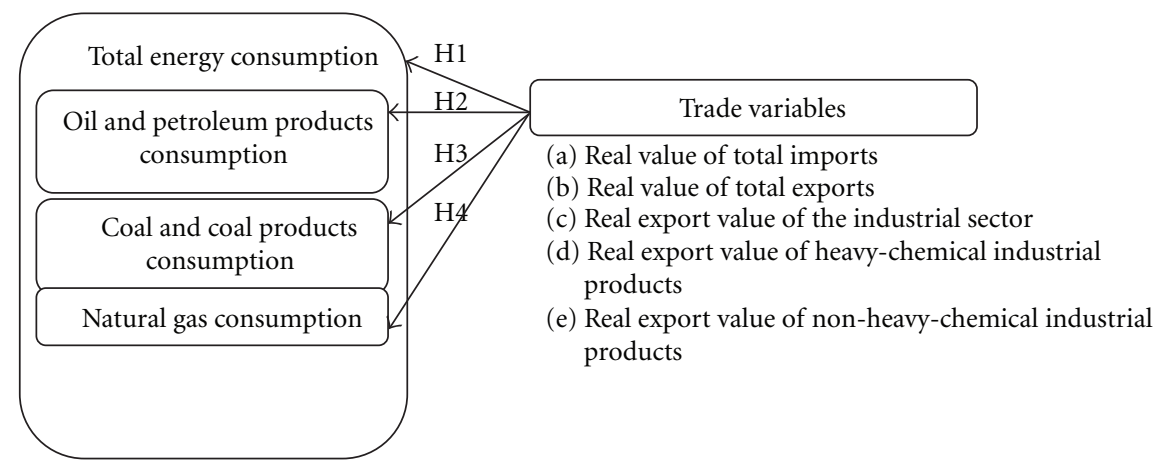

Figure 3: Research framework.

Bowden and Payne [12] find a causal relationship running from energy consumption to GDP in the USA during 19492006.

The second group suggests the causal relationship running from economic growth to energy consumption and call it "the conservation hypothesis." Cheng and Lai [13] and Zhang and Cheng [14] follow Hsiao's [15] version of the Granger causality approach to find a causal linkage running from GDP to energy consumption in Taiwan during 1955-1993 and in China during 1960-2007. Ang [16] also uses the cointegration approach and VEC model to observe causal relations running from GDP to energy consumption in Malaysia during 1971-1999.

The third group finds that there is no causality between energy consumption and economic growth and call this "the neutrality hypothesis." Fatai et al. [17] establish no causal relations between energy consumption and GDP in New Zealand during 1960-1999. Payne [18] observes no causal linkage between energy consumption and economic growth in the USA under different approaches and periods.

The fourth type in the literature concludes that there is bidirectional causality between energy consumption and economic growth, or the so-called "feedback hypothesis". Hondroyiannis et al. [19] explore the linkage between energy consumption, economic growth, and the consumer price index (CPI) for Greece during 1960-1996 and find a longrun relationship among them and a bidirectional causality between energy consumption and economic growth. Erdal et al. [20] and Belloumi [21] observe a bidirectional causality between energy consumption and GDP.

In summary, the existing literature discussed above mainly focuses on the relationship between economic output and energy consumption. To our best knowledge, no academic study examines the relations between international trade and energy consumption. Nevertheless, Ghartey [6] and Kwan et al. [7] claim that international trade could play an important role in the economic growth of Taiwan. Furthermore, Mongelli et al. [22] argue that there are strong dynamic interrelationships between output, energy consumption, environmental pollutants, and foreign trade, which should be investigated in the same multivariate framework.
The main objective of this study is therefore to discuss whether a high dependence of energy consumption has an apparent influence on trade activities' performance in Taiwan. This study examines Hsiao's [15] version of the Granger causality between trade and a variety of imported energy consumption for Taiwan in the vector autoregression (VAR) framework. Figure 3 is the framework of this study. This paper discusses the relations and directions between various trade and energy consumption variables. Trade variables include the real value of total imports, real value of total exports, real export value of the industrial sector, heavy-chemical industrial products, and non-heavychemical industrial products. Energy consumption variables include total energy consumption, oil and petroleum products consumption, coal and coal products consumption, and natural gas consumption.

After a brief literature review, this study provides Hypothesis 1a to Hypothesis 1e.

Hypothesis 1a. There is no Granger causal relation between total energy consumption and the real value of total imports.

Hypotheses 1b-1e. There is no Granger causal relation between total energy consumption and the real value of export variables.

Recent studies research individual energy consumption with most discussing ideas on electricity and nuclear power, for example, Yoo and Lee [23], Pao [24], Balat [25], Abosedra et al. [26], Apergis and Payne [27], and Wolde-Rufael and Menyah [28]. However, it is rare to find prior studies that discuss petroleum, coal, and natural gas. Zou and Chau [29] examine both the equilibrium relationship and the predictability between oil consumption and economic growth in China. They find that these two variables tend to move together in the long run, and oil consumption could be a useful factor that forecasts changes in the economy in the short run as well as in the long run. Therefore, oil consumption is found to have a great impact on the economy.

Yoo [30] investigates short- and long-run causality issues between coal consumption and economic growth in Republic of Korea, and the overall results show that there exists 
bidirectional causality running from coal consumption to economic growth with feedback. Yoo [31] investigates shortand long-run causality issues between oil consumption and economic growth in Republic of Korea. The results show that bidirectional causality runs there from oil consumption to economic growth, implying that an increase in oil consumption directly affects economic growth and that economic growth also further stimulates oil consumption. Yang [32] uses the Granger causality test on the 1954-1997 data for Taiwan to test the causality issue between coal consumption and economic growth.

There is no literature discussing the causal relations between natural gas consumption and economic variables. Therefore, this study provides Hypothesis 2a to Hypothesis 4e listed as follows.

Hypothesis 2a. There is no Granger causal relation between oil and petroleum products consumption and the real value of total imports.

Hypotheses 2b-2e. There is no Granger causal relation between oil and petroleum products consumption and the real value of export variables.

Hypothesis 3a. There is no Granger causal relation between coal and coal products consumption and the real value of total imports.

Hypotheses $3 \mathrm{~b}-3 \mathrm{e}$. There is no Granger causal relation between coal and coal products consumption and the real value of export variables.

Hypothesis 4a. There is no Granger causal relation between natural gas consumption and the real value of total imports.

Hypotheses $4 \mathrm{~b}-4 \mathrm{e}$. There is no Granger causal relation between natural gas consumption and the real value of export variables.

\section{Econometric Methodology}

This study adopts well-established econometric techniques to examine the casual relationship between international trade and energy consumption in Taiwan. (This study only discusses the pairwise comparisons with energy consumption and trade variables. Hence, this study does not use the cointegration test to observe the long-run relations between variables.) Thus, we briefly describe the main methods, that is, Hsiao's version of the Granger causality test and impulse response analysis with VAR, in the following subsections.

3.1. Granger Causality Test. If the predication of the current value of $Y_{t}$ is improved by including past values of $X_{t}$, then it is supposed that the variable $X_{t}$ Granger causes $Y_{t}$. The main concept for using the Granger test is "predictability" on the causal relations between variables. They can be deemed the lead and backward relations between variables.

This study detects the causal relationships between energy consumption and trade variables by Hsiao's [15] version of the Granger causality test. If two variables are tested to be stationary, then the standard form of the Granger causality approach can be expressed as follows:

$$
\Delta Y_{t}=\alpha_{0}+\sum_{i=1}^{P} \alpha_{i} \Delta Y_{t-i}+u_{1 t}
$$

where $p$ is the order of lags altering from 1 to $P$.

Hsiao's procedure involves two steps to determine the optimum number of own and cross-lagged terms and the direction of causality for variables using the final prediction error (FPE). The first step calculates the sum of squared errors (SSE) for (1) where $i=1,2, \ldots, P$. The $\operatorname{FPE}(p)$ considering the lag terms is obtained in the following equation:

$$
\operatorname{FPE}(p)=\frac{\mathrm{SSE}}{T-p-1}\left(1+\frac{p+1}{T}\right)
$$

where $T$ is the total number of observations and SSE is the sum of squared errors. The minimum FPE is decided by the corresponding SSE and $P^{*}$, which is expressed as $\operatorname{FPE}\left(p^{*}\right)$ to make a comparison in the next step. The second step shifts focus to the following equation:

$$
\Delta Y_{t}=\alpha_{0}+\sum_{i=1}^{P} \alpha_{i} \Delta Y_{t-i}+\sum_{j=1}^{Q} \beta_{j} \Delta X_{t-j}+u_{2 t} .
$$

From the above equation, $Y_{t}$ is defined as a controlled variable, with the order of lags set at $p^{*}$ from (2), and $X_{t}$ is a manipulated variable. According to (3), we estimate the SSE of $Y_{t}$ by altering the lag order of $X_{t}$ from 1 to $Q$ and choose the order producing the smallest FPE, which is denoted as $q^{*}$. Finally, the corresponding two-dimensional FPE is of the form

$$
\operatorname{FPE}\left(p^{*}, q\right)=\frac{\operatorname{SSE}\left(p^{*}, q\right)}{T-p^{*}-q-1}\left(1+\frac{p^{*}+q+1}{T}\right),
$$

where $q$ is known as the lag order of series $X_{t}$ altering from 1 to $Q$ and $p^{*}$ is the optimum number of lags estimated in the preceding step. Summing up the above, we may draw the conclusion that series $X_{t}$ Granger causes series $Y_{t}$, if $\operatorname{FPE}\left(p^{*}, q^{*}\right)$ is smaller than $\operatorname{FPE}\left(p^{*}\right)$.

3.2. Impulse-Response Analysis with VAR. Since many economic empirical works are traditionally established according to the prior knowledge, it was hard to settle upon the proper causality and endogenous-exogenous relationship between variables until the vector autoregression model (VAR) was unfolded by Sims [33]. The VAR model treats every variable as being endogenous and expresses their interaction relationships with multiple regression equations rather than one regression equation. by

The general mathematic form of the VAR model is given

$$
\begin{aligned}
& Y_{t}=\alpha+\sum_{i=1}^{m} \beta_{i} Y_{t-i}+\varepsilon_{t}, \quad E\left(\varepsilon_{t} \varepsilon_{S}\right)=0, \\
& E\left(\varepsilon_{t} \varepsilon_{t}^{\prime}\right)=\sum \neq 0,
\end{aligned}
$$


where $Y_{t}$ is a $n \times 1$ vector of variables, $\beta_{i}$ is $n \times n$ matrices of coefficients, $\alpha$ is a $n \times 1$ vector of intercept terms, and $\varepsilon_{t}$ is a $n \times 1$ vector of disturbances, that is, the process of one-stepahead forecast errors.

To better comprehend the dynamic response pattern in the VAR model, we further employ the impulse responses to trace out the responsiveness of the dependent variables to shocks on each of the variables. In other words, impulse response analysis makes it possible to examine how the variables can be destabilized by shocks that arise from other variables. By utilizing Wold's decomposition theorem, the VAR model can be transformed into the form of a moving average; that is, each variable can be expressed as a linear combination of the current value and previous values of a white noise error term. The process is as follows:

$$
\begin{gathered}
Y_{t}-\sum_{i=1}^{m} \beta_{i} Y_{t-i}=\alpha+\varepsilon_{t}, \\
\left(1-\beta_{1} L-\beta_{2} L^{2}-\cdots-\beta_{m} L^{m}\right) Y_{t}=\alpha+\varepsilon_{t}, \\
Y_{t}=\left(1-\beta_{1} L-\beta_{2} L^{2}-\cdots-\beta_{m} L^{m}\right)^{-1} \alpha, \\
+\left(1-\beta_{1} L-\beta_{2} L^{2}-\cdots-\beta_{m} L^{m}\right)^{-1} \varepsilon t, \\
Y_{t}=\alpha^{\prime}+\sum_{i=0}^{\infty} C_{i} \varepsilon_{t-i} .
\end{gathered}
$$

Here $L$ is the lag operator, $\alpha^{\prime}$ is a $n \times 1$ vector of constants, $C_{i}$ is $n \times n$ matrices, and $C_{0}=I$ is a unit matrix.

The estimated VAR residuals are typically deemed contemporaneously correlated. For dissecting the effects of innovations in one variable uncontaminated by contemporaneous innovations in other variables, one feasible implementation is to apply the Cholesky decomposition to generate triangular orthogonalization matrices.

Equation (5) ensures the following equation:

$$
Y_{t}=\alpha^{t}+\sum_{i=0}^{\infty} C_{i} K K^{-1} \varepsilon_{t-i}
$$

Let $C_{i}{ }^{*}=C_{i} K$ and $e_{t-i}=K^{-1} \varepsilon_{t-i}$. The above equation can be reexpressed as

$$
Y_{t}=\alpha^{t}+\sum_{i=0}^{\infty} C_{i}^{*} e_{t-i},
$$

where $C_{i}{ }^{*}$ is an impact multiplier and $e_{t-i}$ is neither autocorrelated nor contemporaneously correlated.

In this way, each variable can be turned into the function of innovations. These matrices multiplied by the estimated VAR model create uncorrelated residuals, which aid to observe how the coefficients change when the objective variable receives spontaneous shocks from other variables.

\section{Empirical Results}

4.1. Data Sources and Descriptive Statistics. Time series variables over the period from 1998 to 2009 are employed in the empirical tests. Monthly imported energy consumption quantities, including total energy consumption (ENERGY), oil and petroleum products consumption (OIL), coal and coal products consumption (COAL), and natural gas consumption (GAS), are defined in KLOE and obtained from the energy monthly report by the Bureau of Energy [34], Ministry of Economic Affairs, Taiwan, covering a period which extends from 1998:1 to 2009:12.

Since the oil, coal, and natural gas used in Taiwan are almost $100 \%$ imported, this study adopts individual total energy consumption quantity as a substitute for individual imported energy consumption quantity. Trade data, including the real value of total imports (IM), real value of total exports (EX), real export value of the industrial sector (EX_Ind), real export value of heavy-chemical industrial products (EX_HI), and real export value of non-heavychemical industrial products (EX_NHI), are obtained from the National Statistics Database by the Directorate-General of Budget, Accounting and Statistics, Executive Yuan, Taiwan and deflated with the base period of 2005. The data are defined as millions of US dollars. Table 2 provides the descriptive statistics for all imported energy consumption and macroeconomic trade-related variables.

The time series properties of all used variables are checked through the augmented Dickey-Fuller test (ADF) and Phillips-Perron's (PP) unit root-testing procedures. As shown in Table 3, under the testing equation computed with an intercept, GAS is stationary; under testing the equation computed with a linear trend and intercept, EX, ENERGY, COAL, OIL, GAS, EX_I, and EX_HI are stationary; no variable is stationary without intercept and linear trend in levels. The series of IM and EX_NHI appear to contain unit roots in their levels but are stationary after first-order differences, meaning that they are I(1) variables.

4.2. Granger Causality Test. The precondition to apply the standard Granger causality test is that the series of variables need to be stationary. According to the results of the unit root test presented in Table 3, EX, ENERGY, COAL, OIL, GAS, EX_I, and EX_HI are stationary, while IM and EX_NHI appear to contain a unit root in their levels. Therefore, we need to transform these non-stationary variables into difference form to compare with the stationary series in the Granger causality test. The Granger causality test results are listed in Table 4.

The results of the Granger causality test between total energy consumption and trade variables reveal that total energy consumption has a unidirectional Granger causal linkage running to total imports, total exports, the export value of the industrial sector, and the export value of heavychemical industrial products, rejecting Hypotheses 1a-1d.

Through examining the causal relationships between oil and petroleum products consumption and trade variables, this study observes that oil and petroleum products consumption Granger causes total exports and all export values under the industrial sector. On the other hand, coal and coal products consumption is Granger caused by all trade variables. Natural gas consumption is Granger caused 
TABLE 2: Summary of descriptive statistics for each variable.

\begin{tabular}{|c|c|c|c|c|c|}
\hline Variables & IM & EX & ENERGY & OIL & COAL \\
\hline Mean & $14,344.07$ & $14,697.77$ & $8,612,447.00$ & $3,534,980.00$ & $608,598.60$ \\
\hline Median & $14,162.30$ & $14,047.77$ & $8,732,205.00$ & $3,597,263.00$ & $610,022.50$ \\
\hline Maximum & $19,304.83$ & $23,346.08$ & $10,767,180.00$ & $4,520,889.00$ & $817,602.00$ \\
\hline Minimum & $8,873.38$ & $6,682.42$ & $5,835,672.00$ & $2,496,122.00$ & $405,642.00$ \\
\hline Std. dev. & $2,438.75$ & $4,183.41$ & $1,165,938.00$ & $470,136.10$ & $89,032.28$ \\
\hline Skewness & -0.11 & 0.17 & -0.34 & -0.24 & 0.13 \\
\hline Kurtosis & 2.06 & 1.86 & 2.27 & 2.14 & 2.48 \\
\hline Jarque-Bera & 5.61 & 8.45 & 5.93 & 5.82 & 2.02 \\
\hline Variables & GAS & EX_I & EX_HI & EX_NHI & \\
\hline Mean & $196,386.70$ & $14,477.83$ & $11,331.66$ & $3,145.34$ & \\
\hline Median & $193,052.50$ & $13,807.70$ & $11,277.06$ & $3,228.32$ & \\
\hline Maximum & $265,803.00$ & $23,160.29$ & $19,793.93$ & $4,061.47$ & \\
\hline Minimum & $161,029.00$ & $6,453.43$ & $3,894.20$ & $1,933.31$ & \\
\hline Std. dev. & $18,147.55$ & $4,211.12$ & $4,225.56$ & 350.29 & \\
\hline Skewness & 0.67 & 0.17 & 0.16 & -0.90 & \\
\hline Kurtosis & 3.52 & 1.86 & 1.78 & 3.99 & \\
\hline Jarque-Bera & 12.53 & 8.45 & 9.56 & 25.09 & \\
\hline
\end{tabular}

Note: IM is total imports; EX is total exports; ENERGY is total energy consumption; OIL is oil and petroleum products consumption; COAL is coal and coal products consumption; GAS is natural gas consumption; EXI is the export value of the industrial sector; EX_HI is the export value of heavy-chemical industrial products; EX_NHI is the export value of non-heavy-chemical industrial products.

TABLE 3: Results of unit root tests.

\begin{tabular}{|c|c|c|c|c|c|c|c|c|c|}
\hline Variable & IM & EX & ENERGY & COAL & OIL & GAS & EX_I & EX_HI & EX_NHI \\
\hline \multicolumn{10}{|c|}{ Level } \\
\hline \multicolumn{10}{|l|}{$\mathrm{ADF}$} \\
\hline$T_{u}$ & -2.23 & -1.65 & -1.58 & -2.28 & -2.62 & $-5.43^{* * *}$ & -1.63 & -1.23 & -2.34 \\
\hline$T_{t}$ & -2.79 & $-3.84^{* *}$ & $-3.76^{* *}$ & $-4.58^{* * *}$ & $-4.14^{* * *}$ & $-5.55^{* * *}$ & $-3.80^{* *}$ & $-3.56^{* *}$ & -2.97 \\
\hline$T$ & 0.12 & 0.63 & 1.32 & 0.46 & 1.00 & 0.03 & 0.65 & 0.90 & -0.55 \\
\hline \multicolumn{10}{|l|}{ PP } \\
\hline$T_{u}$ & $-4.92^{* * *}$ & -1.99 & $-2.94^{* *}$ & $-3.89 * * *$ & $-2.94^{* *}$ & $-6.02^{* * *}$ & -1.94 & -1.39 & $-8.22^{* * *}$ \\
\hline$T_{t}$ & $-6.18^{* * *}$ & $-5.85^{* * *}$ & $-5.23^{* * *}$ & $-7.51^{* * *}$ & $-5.71^{* * *}$ & $-6.10^{* * *}$ & $-5.79^{* * *}$ & $-5.29^{* * *}$ & $-8.64^{* * *}$ \\
\hline$T$ & 0.28 & 1.23 & 0.64 & 0.58 & 1.36 & -0.06 & 1.30 & 1.62 & -0.24 \\
\hline \multicolumn{10}{|c|}{ First difference } \\
\hline \multicolumn{10}{|l|}{$\mathrm{ADF}$} \\
\hline$T_{u}$ & $-14.54^{* * *}$ & $-18.64^{* * *}$ & $-3.20 * *$ & $-13.07^{* * *}$ & $-3.84^{* * *}$ & $-17.86^{* * *}$ & $-18.67 * * *$ & $-18.21^{* * *}$ & $-3.32 * *$ \\
\hline$T_{t}$ & $-14.49^{* * *}$ & $-18.58^{* * *}$ & -3.21 & $-13.03^{* * *}$ & $-3.86^{* *}$ & $-17.89 * * *$ & $-18.60^{* * *}$ & $-18.15^{* * *}$ & -3.41 \\
\hline$T$ & $-14.58^{* * *}$ & $-18.59^{* * *}$ & $-2.82^{* * *}$ & $-13.07^{* * *}$ & $-17.47^{* * *}$ & $-17.92^{* * *}$ & $-18.61^{* * *}$ & $-18.10^{* * *}$ & $-3.31^{* * *}$ \\
\hline \multicolumn{10}{|l|}{ PP } \\
\hline$T_{u}$ & $-29.08^{* * *}$ & $-26.19^{* * *}$ & $-17.03^{* * *}$ & $-28.54^{* * *}$ & $-23.22 * * *$ & $-18.02^{* * *}$ & $-25.57^{* * *}$ & $-22.45^{* * *}$ & $-60.55^{* * *}$ \\
\hline$T_{t}$ & $-29.57^{* * *}$ & $-26.33^{* * *}$ & $-16.90^{* * *}$ & $-28.70^{* * *}$ & $-23.51^{* * *}$ & $-18.09^{* * *}$ & $-25.69^{* * *}$ & $-22.38^{* * *}$ & $-84.14^{* * *}$ \\
\hline$T$ & $-28.76^{* * *}$ & $-22.43^{* * *}$ & $-17.01^{*}$ & $-27.23^{* * *}$ & $-22.20^{* * *}$ & $-18.08^{* * *}$ & $-22.19^{* * *}$ & $-19.39^{* * *}$ & $-61.41^{* * *}$ \\
\hline
\end{tabular}

Note: $(1) * * *$ and $* *$ represent significance at the $1 \%$ and $5 \%$ levels, respectively.

(2) The numbers shown in this table represent $t$-value. $T_{u}, T_{t}$, and $T$, respectively, denote the test equation computed with intercept, with linear trend and intercept and without intercept and linear trend. ADF and PP stand for augmented Dickey-Fuller and Phillips and Perron unit root tests, where the same critical values at $5 \%$ are $-2.86,-3.14,-1.94$ and at $1 \%$ are $-3.43,-3.96,-2.57$, respectively.

by total exports, the export value of the industrial sector, and the export value of heavy-chemical industrial products. Furthermore, pair variables, that is, GAS and EX_NHI as well as GAS and EX_HI, both present a bidirectional causality, implying that there exists a feedback relationship between these pair variables.
4.3. Impulse-Response Simulations. In order to obtain additional insights into how the volatility of energy consumption variables to trade variables has causal relations running from one to the other, we conduct impulse response analysis. (The impulse response analysis is based on the results of VAR, though we do not provide the estimation results of VAR 
TABLE 4: Granger causality test results of the third part of the frameworks.

\begin{tabular}{|c|c|c|c|}
\hline Null hypothesis & $F$-statistic & Probability & Result \\
\hline ENERGY does not Granger cause $\Delta \mathrm{IM}$ & 3.01185 & 0.0525 & Rejected* \\
\hline$\Delta \mathrm{IM}$ does not Granger cause ENERGY & 0.90554 & 0.4067 & Accepted \\
\hline ENERGY does not Granger cause EX & 4.67160 & 0.0109 & Rejected** \\
\hline EX does not Granger cause ENERGY & 0.87260 & 0.4202 & Accepted \\
\hline ENERGY does not Granger cause EX_I & 4.55679 & 0.0121 & Rejected $^{* *}$ \\
\hline EX_I does not Granger cause ENERGY & 0.92758 & 0.3980 & Accepted \\
\hline ENERGY does not Granger cause EX_HI & 4.24986 & 0.0162 & Rejected $^{* *}$ \\
\hline EX_HI does not Granger cause ENERGY & 1.48400 & 0.2304 & Accepted \\
\hline ENERGY does not Granger cause $\Delta$ EX_NHI & 1.66973 & 0.1766 & Accepted \\
\hline$\triangle \mathrm{EX} \_$NHI does not Granger cause ENERGY & 0.38545 & 0.7637 & Accepted \\
\hline OIL does not Granger cause $\Delta \mathrm{IM}$ & 3.61486 & 0.0295 & Rejected** \\
\hline$\Delta \mathrm{IM}$ does not Granger cause OIL & 0.21409 & 0.8075 & Accepted \\
\hline OIL does not Granger cause EX & 9.13576 & 0.0002 & Rejected $^{* * *}$ \\
\hline EX does not Granger cause OIL & 1.31452 & 0.2720 & Accepted \\
\hline OIL does not Granger cause EX_I & 9.11179 & 0.0002 & Rejected $^{* * *}$ \\
\hline EX_I does not Granger cause OIL & 1.42001 & 0.2452 & Accepted \\
\hline OIL does not Granger cause EX_HI & 8.40103 & 0.0004 & Rejected $^{* * *}$ \\
\hline EX_HI does not Granger cause OIL & 2.07448 & 0.1296 & Accepted \\
\hline OIL does not Granger cause $\Delta \mathrm{EX} \_\mathrm{NHI}$ & 4.45012 & 0.0052 & Rejected $^{* * *}$ \\
\hline$\Delta \mathrm{EX} \_$NHI does not Granger cause OIL & 1.26568 & 0.2888 & Accepted \\
\hline COAL does not Granger cause $\triangle \mathrm{IM}$ & 1.49041 & 0.2289 & Accepted \\
\hline$\triangle \mathrm{IM}$ does not Granger cause COAL & 7.77420 & 0.0006 & Rejected ${ }^{* * *}$ \\
\hline COAL does not Granger cause EX & 1.30278 & 0.2762 & Accepted \\
\hline EX does not Granger cause COAL & 7.48613 & 0.0001 & Rejected ${ }^{* * *}$ \\
\hline COAL does not Granger cause EX_I & 1.29781 & 0.2779 & Accepted \\
\hline EX_I does not Granger cause COAL & 7.67668 & $<0.001$ & Rejected $^{* * *}$ \\
\hline COAL does not Granger cause EX_HI & 2.28715 & 0.1054 & Accepted \\
\hline EX_HI does not Granger cause COAL & 9.02300 & 0.0002 & Rejected $^{* * *}$ \\
\hline COAL does not Granger cause $\Delta$ EX_NHI & 0.98330 & 0.4028 & Accepted \\
\hline$\Delta \mathrm{EX} \_N H I$ does not Granger cause COAL & 3.38181 & 0.0202 & Rejected $^{* *}$ \\
\hline GAS does not Granger cause $\Delta \mathrm{IM}$ & 2.32756 & 0.1014 & Accepted \\
\hline$\Delta \mathrm{IM}$ does not Granger cause GAS & 1.33712 & 0.2660 & Accepted \\
\hline GAS does not Granger cause EX & 2.17586 & 0.1174 & Accepted \\
\hline EX does not Granger cause GAS & 4.70585 & 0.0106 & Rejected $^{* *}$ \\
\hline GAS does not Granger cause EX_I & 2.12137 & 0.1238 & Accepted \\
\hline EX_I does not Granger cause GAS & 4.73500 & 0.0103 & Rejected $^{* *}$ \\
\hline GAS does not Granger cause EX_HI & 2.37697 & 0.0966 & Rejected* \\
\hline EX_HI does not Granger cause GAS & 4.41751 & 0.0138 & Rejected $^{* *}$ \\
\hline GAS does not Granger cause $\Delta$ EX_NHI & 4.23376 & 0.0068 & Rejected $^{* * *}$ \\
\hline$\Delta$ EX_NHI does not Granger cause GAS & 4.39757 & 0.0055 & Rejected $^{* * *}$ \\
\hline
\end{tabular}

Note: (1) $* * *, * *$, and * represent significance at the $1 \%, 5 \%$, and $10 \%$ levels, respectively.

(2) $\Delta$ denotes the nonstationary series variable after first-order differences. 

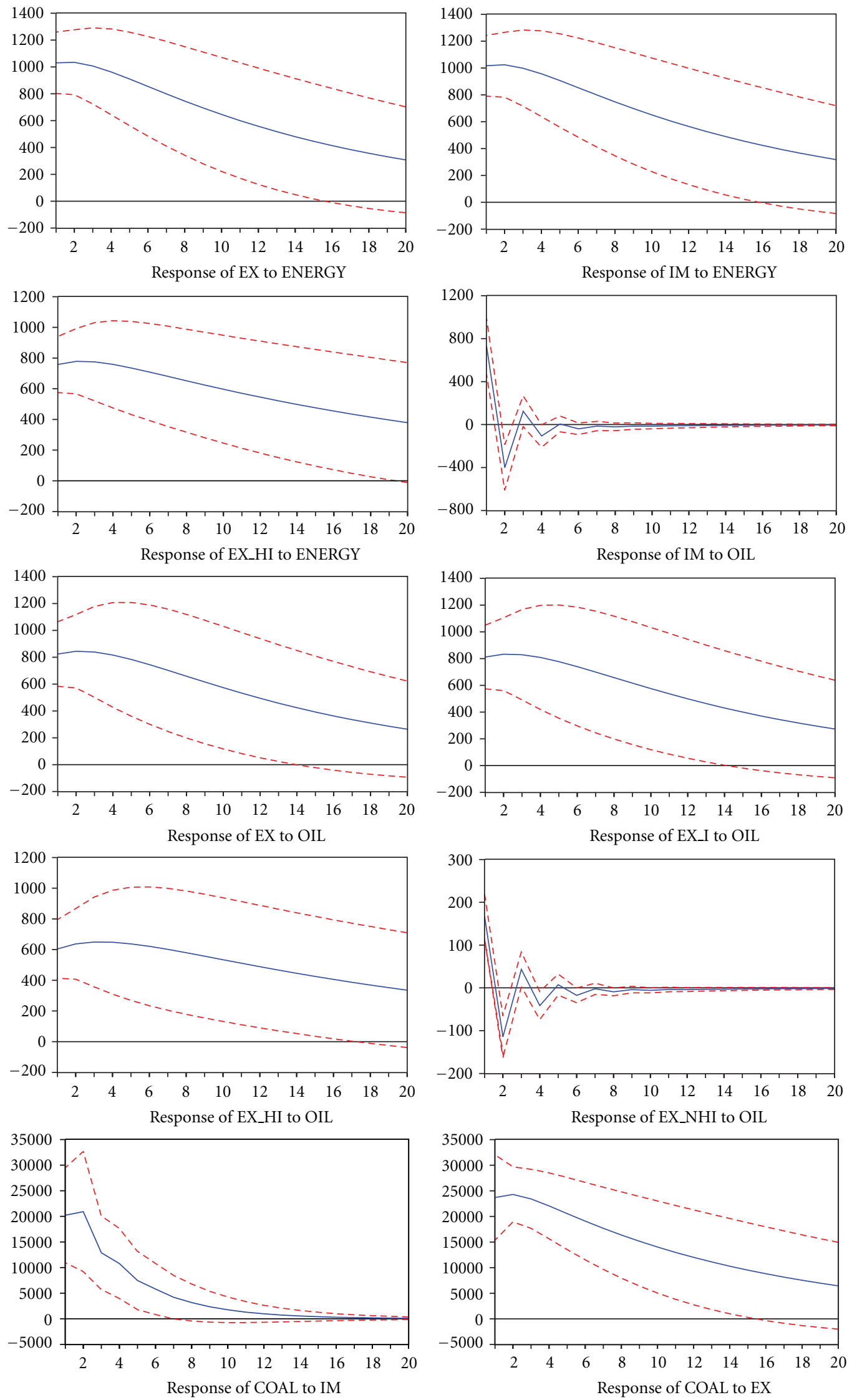

FIgure 4: Continued. 



FIGURE 4: Impulses-responses of variables with the Granger causal relations.

in this paper. We consider that the impulse response analysis can present the relations among all variables more directly and intuitively.) Before establishing impulse-response simulations, we have to choose an optimal lag order of the VAR model. The optimal lag order of the VAR model is selected as 1 on the basis of SBC. Impulse response analysis makes it possible to examine how the variables can be destabilized by shocks that arise with other variables.

Figure 4 presents the results of the variables, observed with causal relationships in the Granger causality test, from the impulse-response analysis based on VAR (1). It shows the impulse-response paths of variables up to 20 months after a one standard deviation shock is stimulated from others.

As shown in Figure 4, IM, EX, EX_I, and EX_HI tend to have positive responses to the shock of total energy consumption at the initial period and then move smoothly downward to the preshock level. With respect to each energy type, IM and EX_NHI tend to have negative responses to the shock of OIL as well as fluctuate up and down around the preshock level and then become stable gradually. 
Furthermore, EX, EX_I, and EX_HI have positive responses to oil consumption at the initial period, and the trend to approach the preshock level moves downward smoothly.

To discuss the responses of energy consumption which is shocked by all trade variables, COAL tends to have positive responses to the shock of EX, EX_I, and EX_HI at the initial period. These curves also move downward to the preshock level smoothly. In addition, coal consumption shows a positive response to the shock of IM and EX_NHI, while coal consumption stabilizes in 2 quarters.

On the other hand, total exports, the export value of the industrial sector, and the export value of heavy-chemical industrial sector all impulse natural gas consumption with positive response directions and converge to preshock levels after one quarter. Furthermore, natural gas consumption and the real value of non-heavy-chemical industrial products impact each other negatively, fluctuate up and down around the preshock level gradually, and become stable during the period.

\section{Discussions and Conclusions}

Previous studies have mainly addressed the relationship between economic growth and energy consumption, while no studies in the literature further discuss the casual relation between trade variables and energy consumption. This paper tries to fill up the gap of prior research studies and to examine the casual relation between trade variables and energy consumption in Taiwan's case, which is a good example since its dependence on imported energy is nearly $100 \%$.

This paper investigates the relation between four energy consumption variables (i.e., total energy consumption, oil consumption, coal consumption, and natural gas consumption) and five trade variables, including total imports, total exports, and the export values of the industrial sector, heavychemical industry, and non-heavy-chemical industry. The results of total energy consumption and oil consumption are similar. In general, all export-related variables tend to positively respond to total energy consumption and oil consumption. This indicates that increasing total energy consumption and oil consumption may cause economics growth in Taiwan. In other words, it presents Taiwan as an input-driven economy.

This paper also shows that there are unidirectional Granger causal linkages running from all trade variables to coal consumption. It is likely that the greater the industrial sector production value is, the greater the coal demand will be in the next period, implying that coal is one of the major raw materials of the industrial sector. Once we separate the industrial sector into two parts, the heavy-chemical industrial sector and the non-heavy-chemical industrial sector, this study finds both of their values of export products Granger cause coal consumption negatively.

Finally, this study finds bidirectional causality between natural gas consumption and the export value of heavychemical industrial products as well as non-heavy-chemical industrial products. Both shock directions in this Granger causal relationship are negative. It seems that the development of the heavy-chemical industry and non-heavy chemical industries has a close relation with natural gas consumption. Since no research has discussed this before, this study sees it as a kind of index to predict the development of these industries. For example, if the consumption of natural gas arises, the development of the non-heavychemical industry will probably increase.

This paper does detect some uni- and bidirectional Granger causalities between disaggregation energy consumption and the trade variables. Therefore, we propose that a new term, "trade-energy policy", should be taken into consideration under Taiwan's energy and international trade policies simultaneously. From the viewpoint of an energy policy, increasing energy consumption will shape national security, economic development, and carbon dioxide emission. Although an energy-saving policy can decrease $\mathrm{CO}_{2}$ emission and ease the pressure of global warming, it will reduce Taiwan's export value and GDP at the same time. From the viewpoint of trade policy, increasing the export value will expand Taiwan's coal demand. Expanding coal demand, however, may confront an energy security warning and environmental problems. Hence, we conclude that a combined tradeenergy policy should be promoted for Taiwan's sustainable growth.

\section{Acknowledgments}

The authors thank the seminar participants at National Chia Yi University, the Chinese Cultural University, and the Taiwan Institute of Economic Research for their helpful comments. Financial support from Taiwan's National Science Council (NSC98-2410-H-009-055) is gratefully acknowledged.

\section{References}

[1] Bureau of Energy, Ministry of EconomicAffairs, Taipei, Taiwan, http://web3.moeaboe.gov.tw/ECW/english/home/English.aspx.

[2] Bureau of Energy, Ministry of Economic Affairs, Energy Statistics Handbook, Bureau of Energy, Ministry of Economic Affairs, Taipei, Taiwan, 2007.

[3] Bureau of Energy, Ministry of Economic Affairs, 2009 Energy Statistics Handbook, Bureau of Energy, Ministry of Economic Affairs, Taipei, Taiwan, 2009, http://www.moeaboe .gov.tw/Download/opengovinfo/plan/all/files/EnergyStatistical-DataBook.pdf.

[4] T. Chien and J. L. Hu, "Renewable energy and macroeconomic efficiency of OECD and non-OECD economies," Energy Policy, vol. 35, no. 7, pp. 3606-3615, 2007.

[5] J. L. Hu and C. H. Lin, "Disaggregated energy consumption and GDP in Taiwan: a threshold co-integration analysis," Energy Economics, vol. 30, no. 5, pp. 2342-2358, 2008.

[6] E. E. Ghartey, "Causal relationship between exports and economic growth: some empirical evidence in Taiwan, Japan and the US," Applied Economics, vol. 25, no. 9, pp. 1145-1152, 1993. 
[7] A. C. C. Kwan, J. A. Cotsomitis, and B. Kwok, "Exports, economic growth and exogeneity: Taiwan 1953-88," Applied Economics, vol. 28, no. 4, pp. 467-471, 1996.

[8] N. S. Shirazi and T. A. A. Manap, "Export-led growth hypothesis: further econometric evidence from South Asia," Developing Economies, vol. 43, no. 4, pp. 472-488, 2005.

[9] G. Machado, R. Schaeffer, and E. Worrell, "Energy and carbon embodied in the international trade of Brazil: an input-output approach," Ecological Economics, vol. 39, no. 3, pp. 409-424, 2001.

[10] J. Kraft and A. Kraft, "On the relationship between energy and GNP," Journal of Energy and Development, vol. 3, no. 2, pp. 401-403, 1978.

[11] J. B. Ang, " $\mathrm{CO}_{2}$ emissions, energy consumption, and output in France," Energy Policy, vol. 35, no. 10, pp. 4772-4778, 2007.

[12] N. Bowden and J. E. Payne, "The causal relationship between U.S. energy consumption and real output: a disaggregated analysis," Journal of Policy Modeling, vol. 31, no. 2, pp. 180$188,2009$.

[13] B. S. Cheng and T. W. Lai, "An investigation of co-integration and causality between energy consumption and economic activity in Taiwan," Energy Economics, vol. 19, no. 4, pp. 435444, 1997.

[14] X. P. Zhang and X. M. Cheng, "Energy consumption, carbon emissions, and economic growth in China," Ecological Economics, vol. 68, no. 10, pp. 2706-2712, 2009.

[15] C. Hsiao, "Autoregressive modelling and money-income causality detection," Journal of Monetary Economics, vol. 7, no. 1, pp. 85-106, 1981.

[16] J. B. Ang, "Economic development, pollutant emissions and energy consumption in Malaysia," Journal of Policy Modeling, vol. 30, no. 2, pp. 271-278, 2008.

[17] K. Fatai, L. Oxley, and F. Scrimgeour, "Energy consumption and employment in New Zealand: searching for causality," in Proceedings of the New Zealand Association of Economists Conference (NZAE'02), Wellington, New Zealand, 2002.

[18] J. E. Payne, "On the dynamics of energy consumption and output in the US," Applied Energy, vol. 86, no. 4, pp. 575-577, 2009.

[19] G. Hondroyiannis, S. Lolos, and E. Papapetrou, "Energy consumption and economic growth: assessing the evidence from Greece," Energy Economics, vol. 24, no. 4, pp. 319-336, 2002.

[20] G. Erdal, H. Erdal, and K. Esengün, "The causality between energy consumption and economic growth in Turkey," Energy Policy, vol. 36, no. 10, pp. 3838-3842, 2008.

[21] M. Belloumi, "Energy consumption and GDP in Tunisia: cointegration and causality analysis," Energy Policy, vol. 37, no. 7, pp. 2745-2753, 2009.

[22] I. Mongelli, G. Tassielli, and B. Notarnicola, "Global warming agreements, international trade and energy/carbon embodiments: an input-output approach to the Italian case," Energy Policy, vol. 34, no. 1, pp. 88-100, 2006.

[23] S. H. Yoo and J. S. Lee, "Electricity consumption and economic growth: a cross-country analysis," Energy Policy, vol. 38, no. 1, pp. 622-625, 2010.

[24] H. T. Pao, "Forecast of electricity consumption and economic growth in Taiwan by state space modeling," Energy, vol. 34, no. 11, pp. 1779-1791, 2009.

[25] M. Balat, "Electricity consumption and economic growth in Turkey: a case study," Energy Sources, Part B, vol. 4, no. 2, pp. 155-165, 2009.
[26] S. Abosedra, A. Dah, and S. Ghosh, "Electricity consumption and economic growth, the case of Lebanon," Applied Energy, vol. 86, no. 4, pp. 429-432, 2009.

[27] N. Apergis and J. E. Payne, "A panel study of nuclear energy consumption and economic growth," Energy Economics, vol. 32, no. 3, pp. 545-549, 2010.

[28] Y. Wolde-Rufael and K. Menyah, "Nuclear energy consumption and economic growth in nine developed countries," Energy Economics, vol. 32, no. 3, pp. 550-556, 2010.

[29] G. Zou and K. W. Chau, "Short- and long-run effects between oil consumption and economic growth in China," Energy Policy, vol. 34, no. 18, pp. 3644-3655, 2006.

[30] S. H. Yoo, "Causal relationship between coal consumption and economic growth in Korea," Applied Energy, vol. 83, no. 11, pp. 1181-1189, 2006.

[31] S. H. Yoo, "Oil consumption and economic growth: evidence from Korea," Energy Sources, Part B, vol. 1, no. 3, pp. 235-243, 2006.

[32] H. Y. Yang, "Coal consumption and economic growth in Taiwan,” Energy Sources, vol. 22, no. 2, pp. 109-115, 2000.

[33] C. A. Sims, "Macroeconomics and reality," Econometrica, vol. 48, no. 1, pp. 1-47, 1980.

[34] Bureau of Energy, "Energy Statistics Monthly Report," 2009, http://www.moeaboe.gov.tw/opengovinfo/Plan/all/energy_ mthreport/main. 


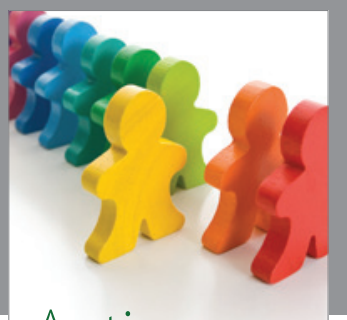

Autism

Research and Treatment
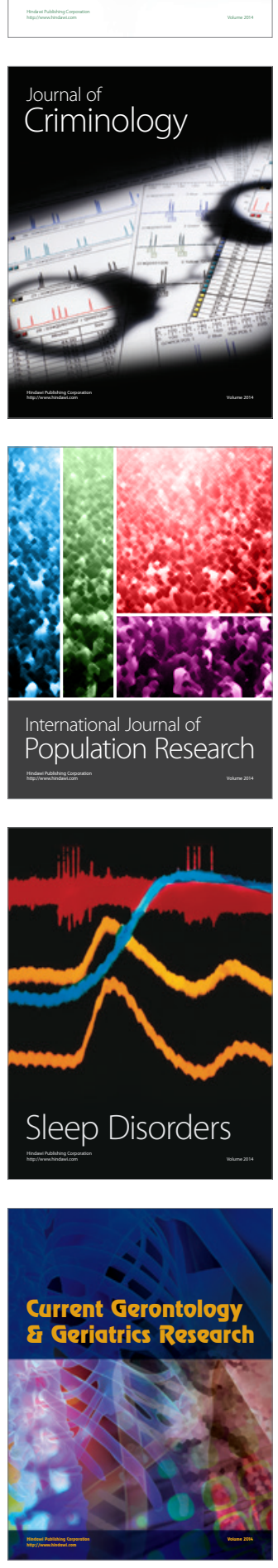
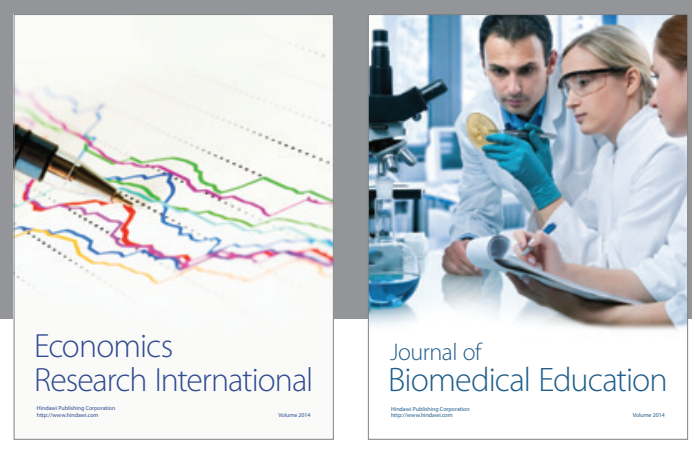

Journal of

Biomedical Education

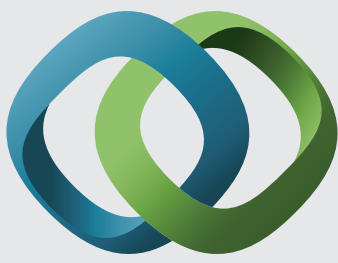

\section{Hindawi}

Submit your manuscripts at

http://www.hindawi.com
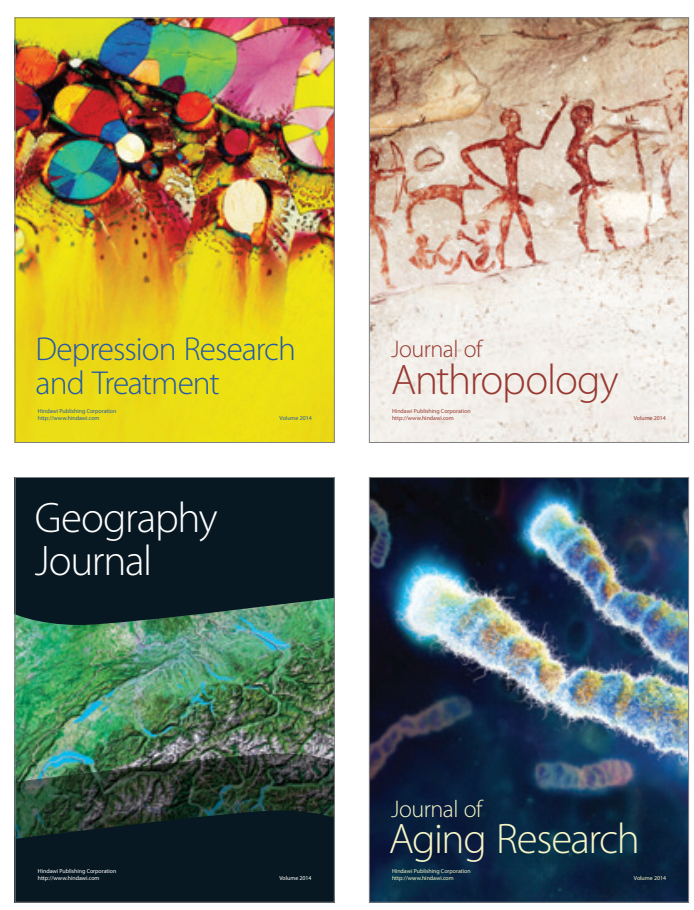

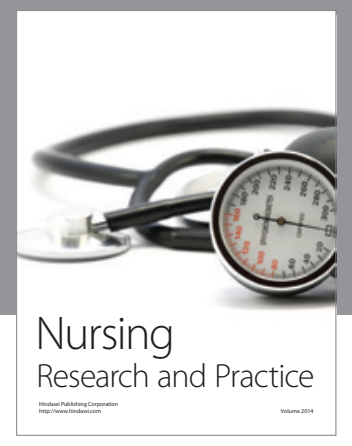

Nursing

Research and Practice

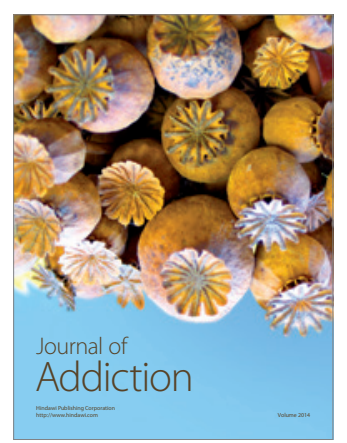

Child Development

Research

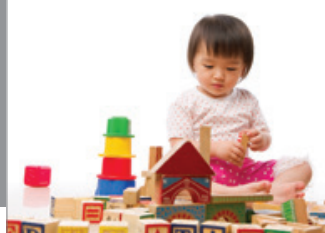

迥
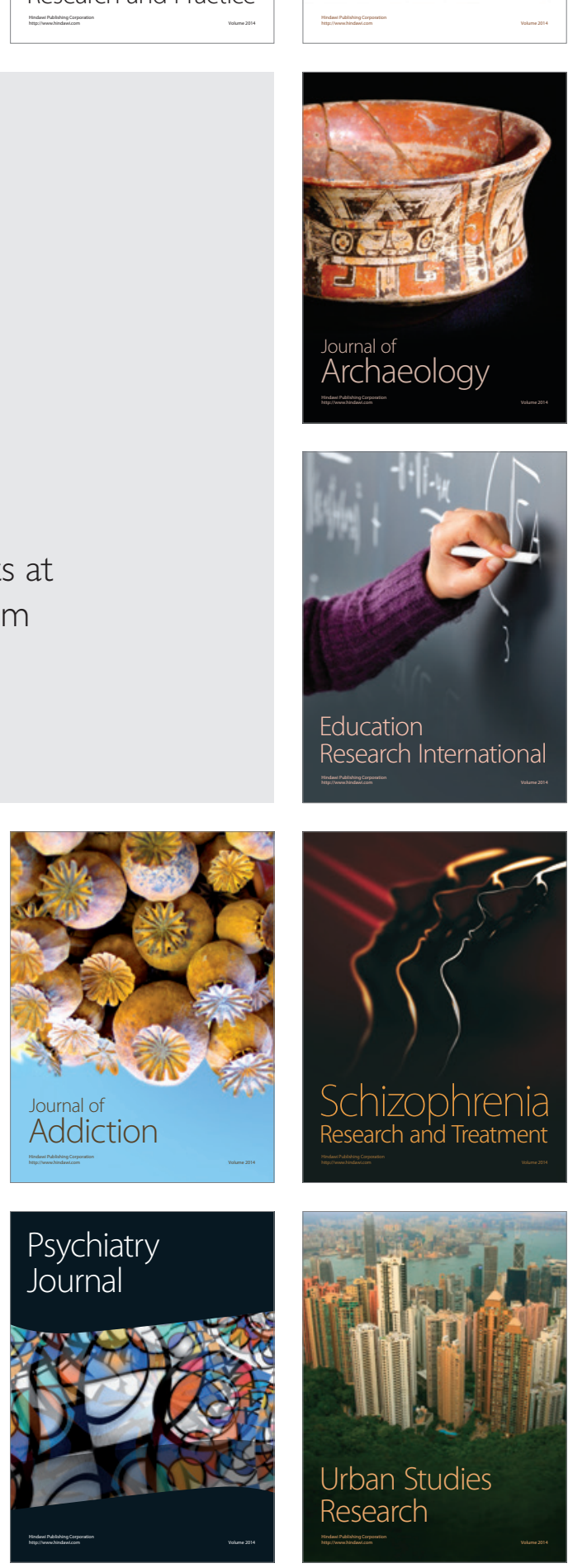